\title{
Leopard syndrome
}

\section{Anna Sarkozy*1, Maria Cristina Digilio² and Bruno Dallapiccola ${ }^{1,3}$}

Address: ${ }^{1}$ IRCCS-CSS, San Giovanni Rotondo and CSS-Mendel Institute, Viale Regina Elena 261, 00198, Rome, Italy, ${ }^{2}$ Medical Genetics, Bambino Gesù Hospital, Piazza San't Onofrio 4, 00165 Rome, Italy and 'Department of Experimental Medicine and Pathology, University "La Sapienza", Viale Regina Elena 261, 00198, Rome, Italy

Email: Anna Sarkozy* - a.sarkozy@css-mendel.it; Maria Cristina Digilio - digilio@opbg.net; Bruno Dallapiccola - dallapiccola@css-mendel.it

* Corresponding author

Published: 27 May 2008

Orphanet Journal of Rare Diseases 2008, 3:13 doi:10.1 I86/I750-I I72-3-13

This article is available from: http://www.ojrd.com/content/3/1//3

(C) 2008 Sarkozy et al; licensee BioMed Central Ltd.

This is an Open Access article distributed under the terms of the Creative Commons Attribution License (http://creativecommons.org/licenses/by/2.0), which permits unrestricted use, distribution, and reproduction in any medium, provided the original work is properly cited.
Received: 6 January 2008

Accepted: 27 May 2008

\begin{abstract}
LEOPARD syndrome (LS, OMIM I5I I00) is a rare multiple congenital anomalies condition, mainly characterized by skin, facial and cardiac anomalies. LEOPARD is an acronym for the major features of this disorder, including multiple Lentigines, ECG conduction abnormalities, Ocular hypertelorism, Pulmonic stenosis, Abnormal genitalia, Retardation of growth, and sensorineural Deafness. About 200 patients have been reported worldwide but the real incidence of LS has not been assessed. Facial dysmorphism includes ocular hypertelorism, palpebral ptosis and low-set ears. Stature is usually below the $25^{\text {th }}$ centile. Cardiac defects, in particular hypertrophic cardiomyopathy mostly involving the left ventricle, and ECG anomalies are common. The lentigines may be congenital, although more frequently manifest by the age of 4-5 years and increase throughout puberty. Additional common features are café-au-lait spots (CLS), chest anomalies, cryptorchidism, delayed puberty, hypotonia, mild developmental delay, sensorineural deafness and learning difficulties. In about $85 \%$ of the cases, a heterozygous missense mutation is detected in exons 7,12 or 13 of the PTPN I I gene. Recently, missense mutations in the RAFI gene have been found in two out of six PTPN I I-negative LS patients. Mutation analysis can be carried out on blood, chorionic villi and amniotic fluid samples. LS is largely overlapping Noonan syndrome and, during childhood, Neurofibromatosis type I-Noonan syndrome. Diagnostic clues of LS are multiple lentigines and CLS, hypertrophic cardiomyopathy and deafness. Mutation-based differential diagnosis in patients with borderline clinical manifestations is warranted. LS is an autosomal dominant condition, with full penetrance and variable expressivity. If one parent is affected, a $50 \%$ recurrence risk is appropriate. LS should be suspected in foetuses with severe cardiac hypertrophy and prenatal DNA test may be performed. Clinical management should address growth and motor development and congenital anomalies, in particular cardiac defects that should be monitored annually. Hypertrophic cardiomyopathy needs careful risk assessment and prophylaxis against sudden death in patients at risk. Hearing should be evaluated annually until adulthood. With the only exception of ventricular hypertrophy, adults with LS do not require special medical care and long-term prognosis is favourable.
\end{abstract}




\section{Disease name and synonyms}

Leopard syndrome (LS, OMIM 151100) is named based on an acronym, mnemonic for the major features of this disorder: multiple Lentigines, ECG conduction abnormalities, Ocular hypertelorism, Pulmonic stenosis, Abnormal genitalia, Retardation of growth, and sensorineural Deafness $[1,2]$. This disease was also known as Multiple Lentigines syndrome, Cardio-cutaneous syndrome, Moynahan syndrome, Lentiginosis profusa and Progressive Cardiomyopathic Lentiginosis.

\section{Historical notes}

LS was first reported by Zeisler and Becker in 1936, in a 24-year-old woman presenting with multiple lentigines, increasing in number from birth to puberty, pectus carinatum, hypertelorism and prognathism [3]. A few decades later, Gorlin et al. reviewed this disorder and coined the LEOPARD acronym supporting the concept of a more generalised condition [1].

\section{Epidemiology}

LS is a rare condition, but the exact birth prevalence is unknown. Not less than 200 patients have been reported and two reviews published $[1,4]$. Within the group of the so called 'neuro-cardio-facial-cutaneous' (NCFC) syndromes, $\mathrm{LS}$ is probably the second most common disorder after Noonan syndrome (NS) [5]. However, LS is likely underdiagnosed or misdiagnosed as many of its features are mild and the correct diagnosis might be missed in the absence of lentiginosis.

\section{Clinical description}

LS is characterised by the presence of multiple lentigines, although these patients are showing a wide spectrum of features with marked variation in expression $[1,2,4,6]$. As mnemonically suggested by the acronym, the main features include multiple lentigines, facial dysmorphisms, cardiac anomalies, electrocardiographic (ECG) conduction abnormalities, retardation of growth, abnormal genitalia and sensorineural deafness.

\section{Facies}

Facial dysmorphisms are characteristic and change considerably with age, being less striking at birth and in the first infancy, with the most characteristic features becoming evident during childhood (Figure 1). Dysmorphic features can occur or be only mildly expressed in the newborns and infants [7]. Hypertelorism is virtually present in all cases, and flat nasal bridge and dysmorphic ears in about $87 \%$ of the patients. Additional, less frequent, features include palpebral ptosis, thick lips and low-set ears with overfolded helix (50\%), large and everted ears, pterygium colli or redundant neck skin (37\%) [7]. Adult patients usually manifest hypertelorism,

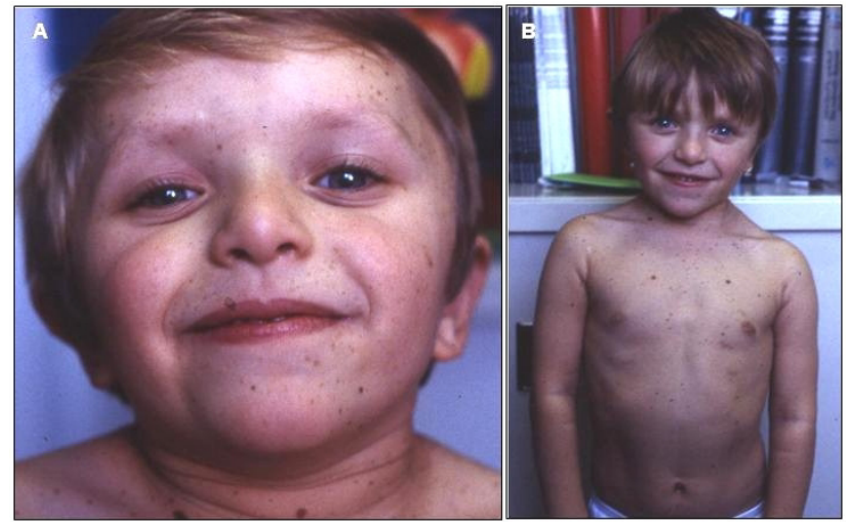

Figure I

Five year-old girl with multiple lentigines, cafe-au-lait spots and dysmorphic features. IA. Note the hyperthelorism, ptosis, blue eyes and low set dysmorphic ears. IB. Note the short neck with pterigium colli, teletelia, pectus excavatum and diffuse lentiginosis on the trunk.

palpebral ptosis, low-set ears, deep nasal-labial folds and premature skin wrinkling.

\section{Cardiovascular system}

Electrocardiographic anomalies and progressive conduction anomalies are the most common heart defects [4,68]. A superiorly oriented mean QRS axis in the frontal plane is frequently observed, even in the absence of structural cardiac abnormalities, and does represent a useful diagnostic handle. A cardiological review indicated that ECG abnormalities occur in about $75 \%$ of the patients, including left or biventricular hypertrophy in $46 \%$ of them, often in association with q waves (19\%), prolonged QTc (23\%) and repolarisation abnormalities (42\%) [8]. Conduction defects are found in $23 \%$ of the patients and p wave abnormalities in $19 \%$. On the whole, about $70 \%$ of LS individuals display cardiac defects [[8]; personal observation]. Previous reports suggested that pulmonary valve stenosis (PVS), with or without dysplasia, is the most common defect $(40 \%)[4,6]$. However, current data points to a consistently lower figure for this defect (10$20 \%)[8,9]$. Conversely, hypertrophic cardiomyopathy (HCM) is the most frequent anomaly and represents the only life-threatening problem in these patients. HCM, which in general is asymmetric and involves the left ventricle, is detected in up to $80 \%$ of the subjects with cardiac defect, and may associate with significant left ventricular outflow tract obstruction in up to $40 \%$ of the cases [[810]; personal data]. Fatal events and sudden death have been reported in LS patients with HCM $[7,8,11,12]$. HCM can be congenital, but frequently manifests during the second infancy $[7,8,12]$. The onset of HCM usually precedes multiple lentigines, but the hypertrophic process may start or often worsen in parallel with lentigines appear- 
ance. Mitral valve prolapse, clefting or other morphological abnormalities have been found in up to $42 \%$ of cases [8]. Less frequent heart defects are atrial and atrioventricular septal defects, coronary artery abnormalities, apical aneurysm and non compaction of the left ventricle, multiple ventricular septal defects, isolated left ventricular enlargement and endocardial fibroelastosis [[6,8]; personal observation].

\section{Skin}

Multiple lentigines are a distinct feature of LS, even if they may be absent in young patients and, quite exceptionally also in subjects older than 5 years [[10]; personal observation] (Figure 1 and 2). Lentigines are flat, black-brown macules, dispersed mostly on the face, neck, and upper part of the trunk, but sparing the mucosae. In general, lentigines appear at 4-5 years and increase into the thousands until puberty, independently from sun exposure
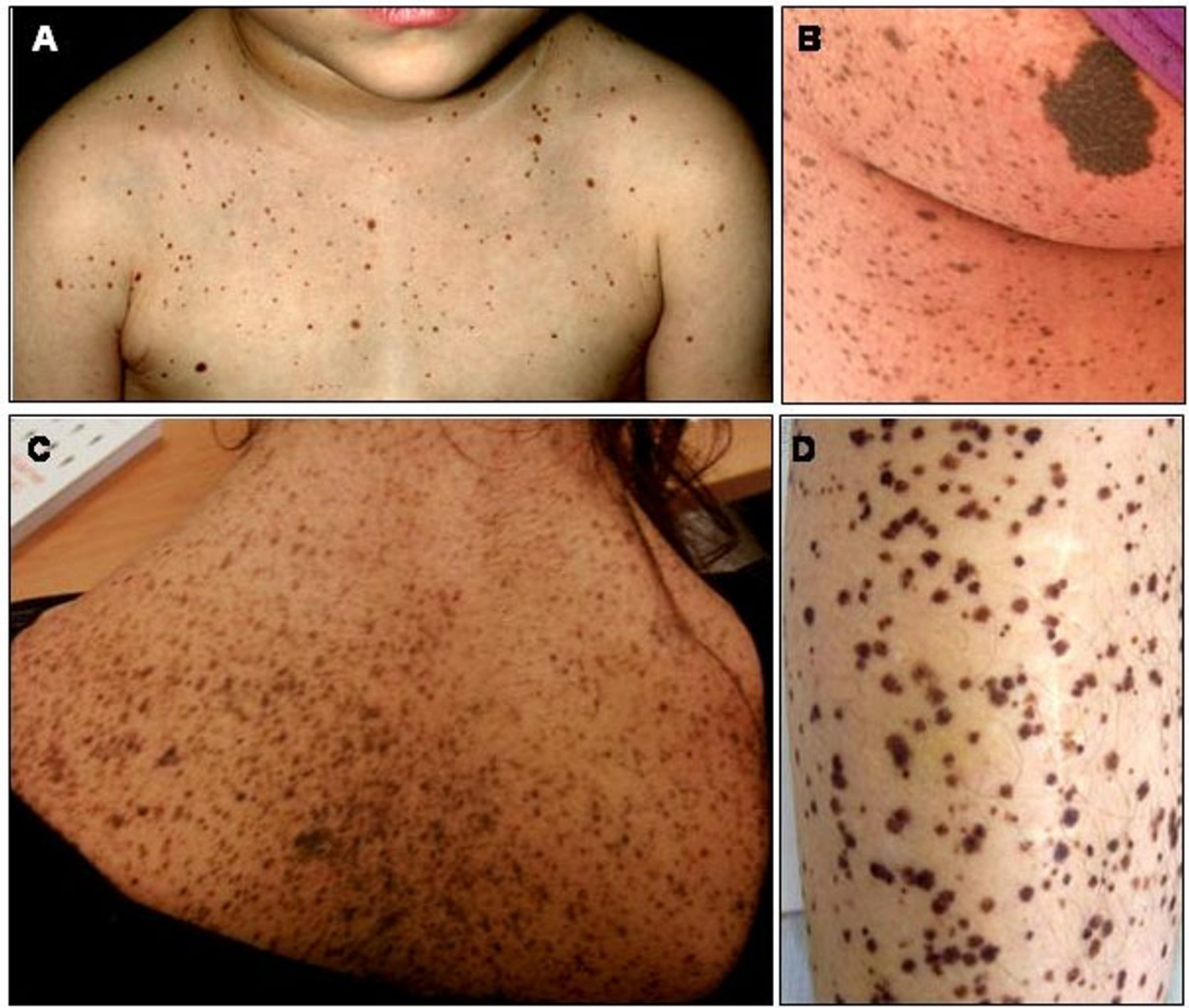

\section{Figure 2}

Skin features of LS individual at different ages. 2A: Numerous lentigines in the upper part of the trunk in a 2 year old child with a PTPN I I gene mutation. 2B. Lentigines and a large cafe-au-lait spot (28 year-old female patient). 2 C. A 28 year old female patient with thousands of lentigines scattered all over the neck and back. Note the pterigium colli. 2D. Multiple lentigines on the lower leg (37 year-old male patient). 
(Figure 2). On histological examination, lentigines are characterised by pigment accumulation in the dermis and deeper epidermal layers, with increased number of melanocytes per unit skin area. The cafe-au-lait spots (CLS), occurring in about half of the patients, are similar to those found in Neurofibromatosis type 1 (NF 1), although they appear much darker in the dark skinned individuals (Figure 2). CLS may be congenital or precede the appearance of lentigines [[10]; personal observation]. Occasional hypopigmented skin areas may also be observed [13].

\section{Weight and length}

Birth weight is normal or above the average in one third of the newborns [10]. Subsequently, LS patients show retardation of growth, with $25 \%$ of cases below the $3^{\text {rd }}$ centile in height and $85 \%$ of adults below the 25 th centile [[4,14]; personal observation].

\section{Skeletal anomalies}

Thorax anomalies, including broad chest, pectus carinatum or excavatum are found in up to $75 \%$ of the newborns [10]. Mandibular prognathism, winging of the scapulae, scoliosis, joint hyperflexibility and other findings are less common [14].

\section{Genital and urinary tract anomalies}

Bilateral cryptorchidism occurs in about $50 \%$ of males, but hypospadia and genital hypoplasia are also frequent. Delayed puberty and hypoplastic ovary have been reported in females. More cases are transmitted through affected mothers suggesting a reduced male fertility. Renal anomalies, including horseshoe kidney, are rare $[4,10]$.

\section{Hearing loss}

Sensorineural deafness occurs in about $15-25 \%$ of patients [6,9]. Most cases are diagnosed at birth or during childhood, but deafness may develop also later in life.

\section{Neurological abnormalities}

Hypotonia is common in the newborn and can result in delayed psychomotor development [10]. Mild learning difficulties are reported in about $30 \%$ of the cases, while mental retardation is rare [[4,10]; personal observation].

\section{Tumours}

Haematological complications, such as myelodysplasia, acute myelogenous leukaemia and neuroblastoma, have been described in a few patients $[4,15,16]$. Malignant melanoma was diagnosed in a patient with a germline PTPN11 and a somatic BRAF mutation [17]. Bilateral choristomas have been reported in a 5-year-old girl [18].

\section{Aetiology}

LS may be sporadic or inherited as an autosomal dominant fully penetrant trait. In approximately $85 \%$ of the patients with a definite diagnosis of LS, a missense mutation is found in the PTPN11 gene, located on chromosome 12q24.1 $[9,19]$. The PTPN11 gene encodes for the SRC homology 2 (SH2) domain-containing PTPase (SHP2) protein, characterised by two tandemly arranged $\mathrm{SH} 2$ (N-SH2 and C-SH2) domains and one protein tyrosine phosphatase (PTP) domain. SHP2 functions as a cytoplasmic signalling transducer downstream of multiple receptors for growth factors, cytokines and hormones, with a particular role through the RAS-mitogen activated protein kinase (MAPK) pathway $[20,21]$. To the best of our knowledge, 11 different missense PTPN11 mutations, in exon 7, 12 and 13 (Tyr279Cys/Ser, Ala461Thr, Gly464Ala, Thr468Met/Pro, Arg498Trp/Leu, Gln506Pro, and Gln510Glu/Gly), have been reported so far, two of which (Tyr279Cys and Thr468Met) occur in about $65 \%$ of the cases [[9,10,22-29], personal data]. Germinal mutations in the PTPN11 gene are also responsible for about $40-50 \%$ of Noonan (NS) and Noonan-like/Multiple Giant Cell lesions syndrome cases [30,31]. Known changes appear to be exclusive for NS or LS, leading to specific genotype-phenotype correlations between these two disorders [23,31]. Among patients with PTPN11 mutations, an association between exon 7 and 12 mutations and HCM, and between exon 8 mutations and PVS, has been established [23]. LS patients without PTPN11 mutations show a higher prevalence of ECG abnormalities and left ventricle hypertrophy [8]. Analyses of the natural history of HCM in LS patients with different genotypes indicate that patients without PTPN11 mutations show a higher frequency of family history of sudden death, increased left atrial dimensions, bradyarrhythmias and other adverse arrhythmic and nonarrhythmic events [12]. Mutations affecting exon 13 in the PTPN11 gene are often associated with an important cardiac phenotype, characterised by rapidly progressive severe biventricular obstructive HCM, often with prenatal onset, and with serious cardiac complications during follow-up (heart failure, septal myectomy, and sudden death) $[12,28,32]$. Analysis of personal cohorts of LS patients indicate that mutation of the Thr468 residue is less frequently associated with short stature, compared to mutation of the Tyr279 residue (26\% vs. $47 \%$ ), in which also deafness is more common ( $24 \%$ vs. $9 \%$ ) [personal data]. This data confirm a previous observation of less adverse effects of the Thr468Met mutation on body growth and cardiac development, with lower prevalence of PVS in these patients [33].

Although LS and NS are clinically overlapping conditions, nosological splitting is well supported by distinct functional effects of the disease causing mutation: gain of function in NS and reduced protein tyrosine phosphatase activity in LS, suggestive of a dominant-negative effect [34,35]. 
Genetic heterogeneity was supported by linkage analysis [36], and recently confirmed by the identification of RAF1 gene mutations in two out of six PTPN11 mutation negative LS patients [37]. RAF1 protein is one of the three mammalian RAF isoforms (ARAF, BRAF and CRAF or RAF1), threonine-serine protein kinases with nonredundant developmental functions, acting downstream of RAS [38]. RAF1 gene mutations are also responsible for a subset of NS, $75 \%$ of which develop HCM $[37,39]$. The two LS subjects carrying the Leu613Val and Ser257Leu changes disclosed a full blown LS phenotype, with multiple lentigines, CLS, HCM and delayed puberty [37]. Pandit et al. investigated the functional effect of different RAF1 mutants, including the Leu613Val change, and showed that those associated with HCM had increased kinase activity and enhanced ERK activation [37]. These data reinforce the role of increased RAS signalling in cardiomyocyte hypertrophy pathogenesis and suggest that LS pathogenesis should not be simply related to a reduced RAS signal transduction $[37,40]$.

About $5 \%$ of LS patients of the reported series do not have PTPN11 or RAF1 mutations. Analysis of additional genes encoding for member or the RAS pathway will likely expand the LS genetic heterogeneity.

Distinct missense PTPN11 gene mutations occur as somatic events in myeloid or lymphoid malignancies [[34]; Cosmic database]. Both the spectrum and the distribution of these PTPN11 mutations are different from those documented in LS and related disorders.

\section{Diagnosis and differential diagnosis}

LS is a rare autosomal dominant disease, with high penetrance and marked variable expression, mainly characterised by short stature, facial dysmorphisms, cardiac anomalies and hyperpigmented skin lesions, specifically multiple lentigines and CLS $[1,2,6]$. According to Voron $e t$ al., clinical diagnosis of LS may be suspected in the presence of multiple lentigines and two cardinal features [4]. In the absence of lentiginosis, three features in the patient and the presence of an affected close relative are diagnostic. Since some features manifest with advancing age, the diagnosis may be problematic in very young patients with only partial phenotypes. However, molecular testing is supportive in this difficult task [9]. Digilio et al. suggested that diagnosis of LS in the first months of age can be clinically suspected in the presence of three main features, including HCM, distinct facial dysmorphisms and CLS [10].

LS is one of the so called 'neuro-cardio-facial-cutaneous'(NCFC) syndromes [5], which include some overlapping disorders, such as NS, Neurofibromatosis type 1, Costello syndrome, Cardiofaciocutaneous syndrome and
LS itself, all caused by mutations in some components of the Ras signalling pathway. These subjects display facial anomalies, heart defects and growth retardation, often associated with skin, skeletal and genital anomalies, and variable degree of mental retardation. In addition, each of these conditions present a few distinct features that are useful handles for differential diagnosis.

Except for its most striking feature, i.e. the multiple lentigines, LS largely overlaps with NS [41,42]. While NS patients show more conspicuous facial features in infancy and childhood, PVS (single-ventricle physiology) is the most frequent cardiac defect in this condition, and skin anomalies and deafness have been rarely reported. Conversely, diagnostic clues of LS are the cutaneous manifestations, such as CLS and multiple lentigines, HCM and deafness. The phenotypic overlap between NS and LS may complicate the differential diagnosis in young individuals who have not yet developed lentigines. Molecular diagnosis and long term follow-up are critical in these individuals. In fact, re-examination later in life may reveal the presence of CLS or lentigines, as for a patient with the Tyr279Cys mutation reported by Tartaglia et al. [31,43]. Likewise, detection of a LS-related mutation should shift the diagnosis toward this condition, as suggested by Digilio et al. for the patient reported by Takahashi and colleagues $[8,28,32]$.

LS also displays an important phenotypic overlap with Neurofibromatosis-Noonan syndrome (NFNS), a clinical entity manifesting with the association of facial and cardiac characteristics of NS with clinical features of neurofibromatosis 1, including CLS, neurofibromas, central nervous system and skeletal anomalies $[44,45]$. NFNS is largely caused by NF1 gene mutations [46]. Nevertheless, NFNS may have different potential aetiologies and NFNS phenotype has been described also in patients with mutations in both the NF1 and PTPN11 genes [47] as well as in neurofibromatosis 1 (NF1) patients with Noonan-like features $[48,49]$. In addition, patients with NS-related gene mutations can have pigmentary skin manifestations similar to those present in neurofibromatosis 1. Mutation-based differential diagnosis in patients with borderline clinical manifestations is warranted [50].

\section{Genetic counselling}

LS is caused by heterozygous missense mutations in autosomal genes. Familial cases are commonly reported, and prevalence of transmitting mothers might be related to reduced male fertility. Genetic counselling should include:

- revision of a three generation family tree, with specific enquiries for skin and cardiac anomalies, short stature and learning difficulties; 
- revision of pregnancy and developmental history and schooling;

- examination of growth parameters, facial dysmorphisms, skin, skeleton, joints, heart and external genitalia;

- complete clinical and cardiological examination of parents, inclusive of echocardiogram and ECG, if possible;

- revision of natural history of the condition, its manifestation and clinical variability, occurrence and recurrence risks, and the eventual recommendation for clinical and molecular investigations to confirm the diagnosis;

- management and follow-up, inclusive of available treatments and interventions.

If one of the parents is affected, a $50 \%$ recurrence risk is appropriate. Germinal mutations and autosomal recessive inheritance have not been reported so far. Accordingly, in case of identified de novo mutation in sporadic patients, the recurrence risk for siblings is marginal. Molecular investigation should take into account the PTPN11 gene screening first, and then the RAF1 gene screening in PTPN11-negative individuals.

\section{Antenatal diagnosis}

The prenatal differential diagnosis between NS and LS may be extremely difficult. LS should be suspected in foetuses with a normal karyotype and HCM. If LS is suspected, physical examination of the parents is indicated. If one parent is affected, obstetric ultrasound at different timings and foetal echocardiography at 20 weeks' of gestations is indicated. A DNA test for mutation analysis can be carried out on chorionic villi or amniotic fluid samples.

\section{Management, treatment and prognosis}

Clinical management, follow-up and treatment of LS patients greatly overlaps that of NS $[41,42]$. However, a few issues need to be addressed differently, taking into account the specific clinical problems and needs of LS individuals. Baseline studies at diagnosis should include a complete clinical examination, cardiological, genitourinary and neurological evaluations and hearing assessment. Laboratory studies should include molecular analysis of the PTPN11 and RAF1 genes.

In general, long-term prognosis of LS patients is favourable. In case of cardiac anomalies at diagnosis, a periodic assessment should be performed as recommended by the cardiologist. Otherwise, a complete cardiological assessment should be performed annually and particularly at the appearance of multiple lentigines. Mild PVS has a good prognosis, while severe valvular dysplasia of the pulmonary valve may recommend valvulotomy or valvulec- tomy [8]. As suggested by Limongelli et al., pathologic and clinical findings may be similar in familial HCM and left ventricular hypertrophy associated to LS [8]. Accordingly, LS patients with ventricular hypertrophy may follow familial HCM algorithms [51]. A beta-blockade or calcium channel blockers therapy could be indicated in the case of a significant gradient between the left ventricle and the aorta. In the absence of any improvement, surgical removal of the left ventricular outflow obstruction is indicated. Fatal events occurring in patients with HCM recommend careful risk assessment and prophylaxis against sudden death in patients at risk $[8,12,13]$. Isolated conduction defects should be monitored annually and treated as in the general population. Annual hearing assessment should be performed until adulthood and hearing aids indicated, if needed. During follow-up, growth parameters should be monitored as in NS $[41,42]$. If growth hormone $(\mathrm{GH})$ therapy is started, the cardiac status should be ongoing assessed, in particular in the presence of HCM. In the case of multiple lentigines or CLS, total UVA-UVB protection should be indicated. Genitourinary, musculoskeletal, neurological and orthodontic anomalies should be monitored and treated as for NS [41,42]. In the presence of developmental delay or difficulties at school, an infant stimulation program and alternate teaching method should be initiated. Hypotonia usually is benefiting of physical and occupational therapies. On the whole, most adults with LS do not require special medical care. Males with cryptorchidism in childhood may have fertility problems in adulthood.

\section{Unresolved questions}

The LS phenotype is extremely heterogeneous, ranging from adults with mild facial features and multiple lentigines, to patients with severe HCM, mental retardation, deafness and additional defects. Genotype-phenotype correlation analysis and functional studies are providing answers to these questions. In early childhood and before the appearance of lentigines, diagnosis of LS is sometimes difficult because of the overlap with NS and NFNS. In these patients, a mutation-based diagnosis is recommended.

Presence of patients without PTPN11 and RAF1 mutations further expand genetic heterogeneity of LS and points towards other genes likely involved in the same RASMAPK pathway.

\section{Abbreviations}

LS: LEOPARD syndrome; CLS: cafê-au-lait spots; HCM: hypertrophic cardiomyopathy; NCFC: neuro-cardiofacial-cutaneous; PVS: pulmonary valve stenosis; NS: Noonan syndrome; NFNS: Neurofibromatosis- Noonan syndrome; 


\section{Competing interests}

The authors declare that they have no competing interests.

\section{Authors' contributions}

AS participated in the design of the study, carried out the molecular genetic studies, analyzed clinical and molecular data, and drafted the manuscript, MCD carried out analysis of clinical data and helped to draft the manuscript, BD conceived the study, participated in its design and coordination, and helped to draft the manuscript. All authors read and approved the final manuscript.

\section{Consent}

Written consent was obtained from the patients or by the patient's relative for pubblication. A copy of the written consent is available for review by the Authors of this manuscript.

\section{Acknowledgements}

Written consent for publication was obtained from the patient or their relative. The authors apologise to colleagues whose work was not cited due to limited space. Research in the authors' laboratory is supported in part by grants from the Italian Ministry of Health (Ricerca Corrente 2007 to AS; Ricerca Corrente 2008 to BD; Progetto Programma Italia-Usa "Malattie Rare" to AS) and the Italian Ministry of University and Research (Progetto Ateneo 2007 to BD).

\section{References}

I. Gorlin RJ, Anderson RC, Blaw M: Multiple lentigines syndrome. Am J Dis Child 1969, 17:652-62.

2. Gorlin RJ, Anderson RC, Moller JH: The Leopard (multiple lentigines) syndrome revisited. Birth Defects Orig Artic Ser 1971, 7(4): I I0-5.

3. Zeisler EP, W S: Generalized Lentigo. Arch Dermat Syph 1936, 33:109-25

4. Voron DA, Hatfield HH, Kalkhoff RK: Multiple lentigines syndrome. Case report and review of the literature. Am J Med 1976, 60:447-56.

5. Bentires-Alj M, Kontaridis MI, Neel BG: Stops along the RAS pathway in human genetic disease. Nat Med 2006, I 2:283-5.

6. Coppin BD, Temple IK: Multiple lentigines syndrome (LEOP. ARD syndrome or progressive cardiomyopathic lentiginosis). I Med Genet 1997, 34:582-6.

7. Somerville J, Bonham-Carter RE: The heart in lentiginosis. $\mathrm{Br}$ Heart J 1972, 34:58-66.

8. Limongelli G, Pacileo G, Marino B, Digilio MC, Sarkozy A, Elliott $P$, Versacci P, Calabro P, De Zorzi A, Di Salvo G, Syrris P, Patton M, McKenna WJ, Dallapiccola B, Calabro R: Prevalence and clinical significance of cardiovascular abnormalities in patients with the LEOPARD syndrome. Am J Cardiol 2007, I 00:736-4I.

9. Sarkozy A, Conti E, Digilio MC, Marino B, Morini E, Pacileo G, Wilson M, Calabro R, Pizzuti A, Dallapiccola B: Clinical and molecular analysis of $\mathbf{3 0}$ patients with multiple lentigines LEOPARD syndrome. I Med Genet 2004, 4I:e68.

10. Digilio MC, Sarkozy A, de Zorzi A, Pacileo G, Limongelli G, Mingarelli R, Calabro R, Marino B, Dallapiccola B: LEOPARD syndrome: clinical diagnosis in the first year of life. Am J Med Genet A 2006, I 40:740-6.

II. Woywodt A, Welzel J, Haase H, Duerholz A, Wiegand U, Potratz J, Sheikhzadeh A: Cardiomyopathic lentiginosis/LEOPARD syndrome presenting as sudden cardiac arrest. Chest 1998, II3:14|5-7.

12. Limongelli G, Sarkozy A, Pacileo G, Calabrò P, Digilio MC, Maddaloni V, Gagliardi G, Di Salvo G, lacomino M, Marino B, Dallapiccola B, Calabrò R: Genotype-phenotype analysis and natural history of left ventricular hypertrophy in LEOPARD syndrome. Am J Med Genet A 2008, 46():620-8.
13. Selmanowitz VJ, Orentreich N, Felsenstein JM: Lentiginosis profusa syndrome (multiple lentigines syndrome). Arch Dermatol 1971, 104:393-401.

14. Gorlin JR, Cohen MM, Levn LS: Leopard syndrome. In Syndromes of the head and neck Edited by: Gorlin JR, Cohen MM, Levn LS. New York, Oxford University Press; 1990:46I-4.

15. Ucar C, Calyskan U, Martini S, Heinritz W: Acute myelomonocytic leukemia in a boy with LEOPARD syndrome (PTPN I I gene mutation positive. J Pediatr Hematol Oncol 2007, 28: I 23-5.

16. Merks JH, Caron HN, Hennekam RC: High incidence of malformation syndromes in a series of 1,073 children with cancer. Am J Med Genet A 2005, 134(2): $132-43$.

17. Seishima M, Mizutani Y, Shibuya Y, Arakawa C, Yoshida R, Ogata T: Malignant melanoma in a woman with leopard syndrome: Identification of a germline PTPN I I mutation and a somatic BRAF mutation. Br J Dermatol 2007, I 57: I297-9.

18. Choi WW, Yoo JY, Park KC, Kim KH: Leopard syndrome with a new association of congenital corneal tumor, choristoma. Pediatr Dermatol 2003, 20:158-60.

19. Digilio MC, Conti E, Sarkozy A, Mingarelli R, Dottorini T, Marino B, Pizzuti A, Dallapiccola B: Grouping of multiple-lentigines/LEOP. ARD and Noonan syndromes on the PTPNI I gene. Am J Hum Genet 2002, $71: 389-94$.

20. Neel BG, Gu H, Pao L: The 'Shp'ing news: SH2 domain-containing tyrosine phosphatases in cell signaling. Trends Biochem $\mathrm{Sc}$ 2003, 28:284-93.

21. Tartaglia M, Niemeyer CM, Shannon KM, Loh ML: SHP-2 and myeloid malignancies. Curr Opin Hematol 2004, I I:44-50.

22. Legius E, Schrander-Stumpel C, Schollen E, Pulles-Heintzberger C, Gewillig M, Fryns JP: PTPNII mutations in LEOPARD syndrome. J Med Genet 2002, 39:57|-4.

23. Sarkozy A, Conti E, Seripa D, Digilio MC, Grifone N, Tandoi C, Fazio VM, Di Ciommo V, Marino B, Pizzuti A, Dallapiccola B: Correlation between PTPNII gene mutations and congenital heart defects in Noonan and LEOPARD syndromes. J Med Genet 2003, 40:704-8.

24. Conti E, Dottorini T, Sarkozy A, Tiller GE, Esposito G, Pizzuti A, Dallapiccola B: A novel PTPNII mutation in LEOPARD syndrome. Hum Mutat 2003, 21:654.

25. Yoshida R, Nagai T, Hasegawa T, Kinoshita E, Tanaka T, Ogata T: Two novel and one recurrent PTPN I I mutations in LEOPARD syndrome. Am J Med Genet 2004, I30(4):432-4.

26. Keren B, Hadchouel A, Saba S, Sznajer Y, Bonneau D, Leheup B, Boute O, Gaillard D, Lacombe D, Layet V, Marlin S, Mortier G, Toutain A, Beylot C, Baumann C, Verloes A, Cave H: PTPNII mutations in patients with leopard syndrome: $A$ french multicentric experience. J Med Genet 2004, 41 : el I 7.

27. Sarkozy A, Obregon MG, Conti E, Esposito G, Mingarelli R, Pizzuti A Dallapiccola $B$ : A novel ptpn I I gene mutation bridges noonan syndrome, Multiple Lentigines/LEOPARD syndrome and Noonan- like/Multiple Giant Cell Lesion syndrome. Eur J Hum Genet 2004, I 2:1069-72.

28. Digilio MC, Sarkozy A, Pacileo G, Limongelli G, Marino B, Dallapiccola B: PTPN I I gene mutations: linking the GIn5 I0Glu mutation to the "LEOPARD syndrome phenotype". Eur J Pediatr 2006, 165:803-5.

29. Du-Thanh A, Cave H, Bessis D, Puso C, Guilhou JJ, Dereure O: A novel PTPNII gene mutation in a patient with LEOPARD syndrome. Arch Dermatol 2007, I 43:1210-I.

30. Tartaglia M, Mehler EL, Goldberg R, Zampino G, Brunner HG, Kremer $\mathrm{H}$, Burgt I van der, Crosby AH, lon A, Jeffery S, Kalidas K, Patton MA, Kucherlapati RS, Gelb BD: Mutations in PTPNI I, encoding the protein tyrosine phosphatase SHP- 2, cause Noonan syndrome. Nat Genet 2002, 30:123-6.

3I. Tartaglia M, Gelb BD: Noonan syndrome and related disorders: genetics and pathogenesis. Annu Rev Genomics Hum Genet 2005, 6:45-68.

32. Takahashi K, Kogaki S, Kurotobi S, Nasuno S, Ohta M, Okabe H, Wada K, Sakai N, Taniike M, Ozono K: A novel mutation in the PTPNII gene in a patient with Noonan syndrome and rapidly progressive hypertrophic cardiomyopathy. Eur J Pediatr 2005, 164:497-500.

33. Zenker M, Buheitel G, Rauch R, Koenig R, Bosse K, Kress W, Tietze HU, Doerr HG, Hofbeck M, Singer H, Reis A, Rauch A: Genotypephenotype correlations in Noonan syndrome. J Pediatr 2004 I 44:368-74. 
34. Tartaglia M, Martinelli S, Stella L, Bocchinfuso G, Flex E, Cordeddu V, Zampino G, Burgt I, Palleschi A, Petrucci TC, Sorcini M, Schoch C, Foa R, Emanuel PD, Gelb BD: Diversity and functional consequences of germline and somatic PTPNII mutations in human disease. Am J Hum Genet 2006, 78:279-90.

35. Kontaridis MI, Swanson KD, David FS, Barford D, Neel BG: PTPNI I (Shp2) mutations in LEOPARD syndrome have dominant negative, not activating, effects. J Biol Chem 2006, 281 :6785-92.

36. Kalidas K, Shaw AC, Crosby AH, Newbury-Ecob R, Greenhalgh L, Temple IK, Law C, Patel A, Patton MA, Jeffery S: Genetic heterogeneity in LEOPARD syndrome: two families with no mutations in PTPNI I. J Hum Genet 2005, 50:2I-5.

37. Pandit B, Sarkozy A, Pennacchio LA, Carta C, Oishi K, Martinelli S, Pogna EA, Schackwitz W, Ustaszewska A, Landstrom A, Bos JM, Ommen SR, Esposito G, Lepri F, Faul C, Mundel P, Lopez Siguero JP, Tenconi R, Selicorni A, Rossi C, Mazzanti L, Torrente I, Marino B, Digilio MC, Zampino G, Ackerman MJ, Dallapiccola B, Tartaglia M, Gelb BD: Gain-of-function RAFI mutations cause Noonan and LEOPARD syndromes with hypertrophic cardiomyopathy. Nat Genet 2007, 39:1007-I2.

38. Wellbrock C, Karasarides M, Marais R: The RAF proteins take centre stage. Nat Rev Mol Cell Biol 2004, 5:875-85.

39. Razzaque MA, Nishizawa T, Komoike $Y$, Yagi H, Furutani M, Amo R Kamisago M, Momma K, Katayama H, Nakagawa M, Fujiwara Y, Matsushima M, Mizuno K, Tokuyama M, Hirota H, Muneuchi J, Higashinakagawa T, Matsuoka R: Germline gain-of-function mutations in RAFI cause Noonan syndrome. Nat Gene 2007, 39(8): I0I3-7.

40. Muslin AJ: Role of raf proteins in cardiac hypertrophy and cardiomyocyte survival. Trends Cardiovasc Med 2005, I 5:225-9.

41. Burgt I van der: Noonan syndrome. Orphanet J Rare Dis 2007, 2:4.

42. Allanson J: Noonan syndrome. In Management of Genetic Syndromes Edited by: Cassidy SB, Allanson JE. New York, Wiley-Liss; 2005.

43. Tartaglia M, Kalidas K, Shaw A, Song X, Musat DL, Burgt I van der, Brunner HG, Bertola DR, Crosby A, lon A, Kucherlapati RS, Jeffery S, Patton MA, Gelb BD: PTPN I I mutations in Noonan syndrome: Molecular spectrum, genotype-phenotype correlation, and phenotypic heterogeneity. Am J Hum Genet 2002, 70: 1555-63.

44. Opitz JM, Weaver DD: The neurofibromatosis-Noonan syndrome. Am J Med Genet 1985, 21:477-90.

45. Friedman JM, Birch PH: Type I neurofibromatosis: a descriptive analysis of the disorder in I,728 patients. Am J Med Genet 1997, 70:138-43

46. De Luca A, Bottillo I, Sarkozy A, Carta C, Neri C, Bellacchio E, Schirinzi A, Conti E, Zampino G, Battaglia A, Majore S, Rinaldi MM, Carella M, Marino B, Pizzuti A, Digilio MC, Tartaglia M, Dallapiccola B: NFI gene mutations represent the major molecular event underlying neurofibromatosis-Noonan syndrome. Am J Hum Genet 2005, 77:1092-10I.

47. Bertola DR, Pereira AC, Passetti F, de Oliveira PS, Messiaen L, Gelb BD, Kim CA, Krieger JE: Neurofibromatosis-Noonan syndrome: molecular evidence of the concurrence of both disorders in a patient. Am J Med Genet A 2005, I 36:242-5.

48. Hüffmeier $U$, Zenker $M$, Hoyer J, Fahsold $R$, Rauch A: A variable combination of features of Noonan syndrome and neurofibromatosis type $I$ are caused by mutations in the NFI gene. Am J Med Genet A 2006, I40:2749-56.

49. Stevenson DA, Viskochil DH, Rope AF, Carey JC: Clinical and molecular aspects of an informative family with neurofibromatosis type I and Noonan phenotype. Clin Genet 2006, 69:246-53.

50. Sarkozy A, Schirinzi A, Lepri F, Bottillo I, De Luca A, Pizzuti A, Tartaglia $M$, Digilio MC, Dallapiccola B: Clinical lumping and molecular splitting of LEOPARD and NFI/NFI-Noonan syndromes. Am J Med Genet A 2007, I 43(9): I009-II.

51. Elliott P, McKenna WJ: Hypertrophic cardiomyopathy. Lancet 2004, 363:|88|-9|.

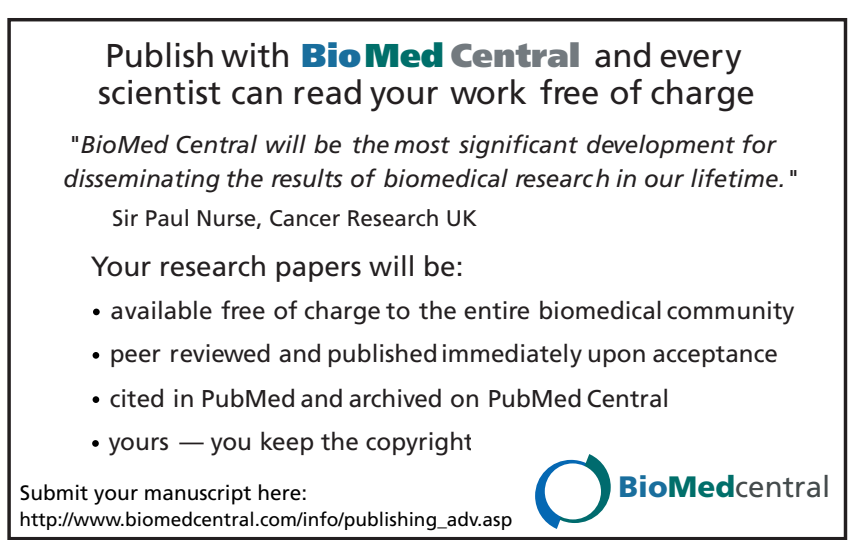

